\title{
Automatic high-frequency measurements of full soil greenhouse gas fluxes in a tropical forest
}

\author{
Elodie Alice Courtois ${ }^{1,2}$, Clément Stahl ${ }^{3}$, Benoit Burban ${ }^{3}$, Joke Van den Berge ${ }^{1}$, Daniel Berveiller ${ }^{4}$, \\ Laëtitia Bréchet $^{1,3}$, Jennifer Larned Soong ${ }^{1,5}$, Nicola Arriga ${ }^{1}$, Josep Peñuelas ${ }^{6,7}$, and Ivan August Janssens ${ }^{1}$ \\ ${ }^{1}$ Department of Biology University of Antwerp, Centers of Excellence Global Change Ecology and PLECO (Plants and \\ Ecosystems), Universiteitsplein 1, 2610 Wilrijk, Belgium \\ ${ }^{2}$ Laboratoire Ecologie, évolution, interactions des systèmes amazoniens (LEEISA), Université de Guyane, CNRS, IFREMER, \\ 97300 Cayenne, French Guiana \\ ${ }^{3}$ INRA, UMR EcoFoG, CNRS, Cirad, AgroParisTech, Université des Antilles, Université de Guyane, 97310 Kourou, France \\ ${ }^{4}$ CNRS/Université Paris-sud, 362 rue du doyen André Guinier, 91405 Orsay CEDEX, France \\ ${ }^{5}$ Climate and Ecosystem Sciences Division, Lawrence Berkeley National Laboratory, 94720, Berkeley, USA \\ ${ }^{6}$ CSIC, Global Ecology Unit CREAF-CSIC-UAB, Bellaterra, 08193 Catalonia, Spain \\ ${ }^{7}$ CREAF, Cerdanyola del Vallès, 08193 Catalonia, Spain
}

Correspondence: Elodie Alice Courtois (elodie.courtois@cnrs.fr)

Received: 16 July 2018 - Discussion started: 15 August 2018

Revised: 23 January 2019 - Accepted: 25 January 2019 - Published: 12 February 2019

\begin{abstract}
Measuring in situ soil fluxes of carbon dioxide $\left(\mathrm{CO}_{2}\right)$, methane $\left(\mathrm{CH}_{4}\right)$, and nitrous oxide $\left(\mathrm{N}_{2} \mathrm{O}\right)$ continuously at high frequency requires appropriate technology. We tested the combination of a commercial automated soil $\mathrm{CO}_{2}$ flux chamber system (LI-8100A) with a $\mathrm{CH}_{4}$ and $\mathrm{N}_{2} \mathrm{O}$ analyzer (Picarro G2308) in a tropical rainforest for 4 months. A chamber closure time of 2 min was sufficient for a reliable estimation of $\mathrm{CO}_{2}$ and $\mathrm{CH}_{4}$ fluxes (100\% and $98.5 \%$ of fluxes were above minimum detectable flux - MDF, respectively). This closure time was generally not suitable for a reliable estimation of the low $\mathrm{N}_{2} \mathrm{O}$ fluxes in this ecosystem but was sufficient for detecting rare major peak events. A closure time of $25 \mathrm{~min}$ was more appropriate for reliable estimation of most $\mathrm{N}_{2} \mathrm{O}$ fluxes $(85.6 \%$ of measured fluxes are above MDF $\left.\pm 0.002 \mathrm{nmol} \mathrm{m}^{-2} \mathrm{~s}^{-1}\right)$. Our study highlights the importance of adjusted closure time for each gas.
\end{abstract}

\section{Introduction}

After water vapor, carbon dioxide $\left(\mathrm{CO}_{2}\right)$, methane $\left(\mathrm{CH}_{4}\right)$, and nitrous oxide $\left(\mathrm{N}_{2} \mathrm{O}\right)$ are the three main greenhouse gases (GHGs) in terms of radiative forcing. Increases in these GHG concentrations in the atmosphere are driving anthro- pogenic global warming. Understanding the magnitude of GHG fluxes in natural ecosystems has recently become a priority in the study of GHG balances (Merbold et al., 2015). Tropical intact forests cover 1392 Mha globally and represent about $70 \%$ of the total tropical forest area (1949 Mha), which accounts for the largest area of global forest biomes $(\sim 50 \%)$. Very few reliable long-term datasets on full GHG balances are available from tropical ecosystems, despite their known importance for the global cycles of these three GHGs (Dutaur and Verchot, 2007). This is in part due to the challenges of designing and operating continuous, multi-gas flux analysis systems in tropical forests. Soil processes in particular are responsible for an important part of GHGs that are produced or consumed in tropical ecosystems (Oertel et al., 2016). Soil physical, chemical, and biological characteristics are linked to variation in GHG emissions from soils, which in turn can display very high spatial and temporal variability (Arias-Navarro et al., 2017; Silver et al., 1999).

Historically, soil GHG fluxes (emission or consumption) have been measured using the static chamber method. This involves closing chambers manually for a known period of time, usually 30-60 min, and repeated collection of air samples for further analysis via gas chromatography (Verchot et al., 1999, 2000). Fluxes are then computed from the change 
in gas concentration per unit of time, per surface area enclosed by the chamber, and corrected by the volume of the chamber. While these labor-intensive and time-consuming manual measurements are well-adapted to capture high spatial flux variability (Arias-Navarro et al., 2017; Pumpanen et al., 2004), they do not capture high temporal variation, which is necessary for the accurate estimation of annual GHG budgets. Moreover, short-term transient spikes in the emission or consumption of these GHGs likely remains undetected with static chamber methods, imposing a lost opportunity to fully understand the production or consumption processes of GHGs and their response to rapidly changing environmental conditions. One of the key challenges of contemporary GHG flux research is to close these knowledge gaps in order to improve the quantitative prediction of GHG fluxes (Merbold et al., 2015).

The use of automatic chambers is one approach to obtain continuous estimation of soil GHG flux data at high temporal frequency (several measurements per days) at various sampling points. Since the 1970s (Denmead, 1979), a variety of technical solutions for automated flux sampling have been developed (Ambus et al., 2010; Breuer et al., 2000; Görres et al., 2016; Kostyanovsky et al., 2018; O'Connell et al., 2018; Petrakis et al., 2017a; Savage et al., 2014), particularly for soil $\mathrm{CO}_{2}$ fluxes. However, accurate detection of $\mathrm{CH}_{4}$ and $\mathrm{N}_{2} \mathrm{O}$ fluxes from soils via flow through systems is more difficult than $\mathrm{CO}_{2}$ due to significantly lower background concentrations and lower flux rates (Kostyanovsky et al., 2018). The budgetary requirements for large infrastructure and intensive maintenance compared to manual chamber measurements have prevented the widespread application of automated systems. The use of automated and continuous methods to estimate full GHG budgets in situ remains scarce, especially in complex biomes with extreme climate such as tropical forests. Therefore, only a few studies actually address the difficulties and challenges associated with operating these systems under field conditions (Görres et al., 2016; Koskinen et al., 2014).

Recent technological advances have now made more automated chamber systems commercially available, and an increasing number of custom-made systems are being designed and deployed for soil GHG flux measurements (De Klein and Harvey, 2012). Here, we present a detailed field deployment of a custom-built automated soil GHG flux system - the LI-8100A Soil $\mathrm{CO}_{2}$ Flux System (LI-COR Biosciences Inc., Lincoln, NE, USA) running in line with a Picarro G2308 (Picarro Inc., Santa Clara, CA, USA). Using a 4-month dataset of continuous measurements of $\mathrm{CO}_{2}, \mathrm{CH}_{4}$, and $\mathrm{N}_{2} \mathrm{O}$ fluxes simultaneously under tropical forest conditions, we present an optimized sampling protocol for the estimation of the full GHG budget in this ecosystem.

\section{Methods}

\subsection{Measurement site}

This study was conducted at the Paracou research station $\left(5^{\circ} 15^{\prime} \mathrm{N}, 52^{\circ} 55^{\prime} \mathrm{W}\right)$, located in the coastal area of French Guiana, South America. The automated soil GHG flux system was deployed in the footprint of the Guyaflux site, which holds a $55 \mathrm{~m}$ tall tower upon which canopy $\mathrm{CO}_{2}, \mathrm{H}_{2} \mathrm{O}$, and energy fluxes have been monitored since 2004 using the eddy covariance technique (Aguilos et al., 2018; Bonal et al., 2008). The site is covered with pristine tropical forest and located in the northernmost part of the Guiana shield. It is characterized by a succession of small elliptical hills rising to $10-40 \mathrm{~m}$ a.s.l., sometimes associated with plateaus of similar altitude.

The soils are mostly nutrient-poor Acrisols (FAO/ISRIC/ISSS, 1998) with pockets of sandy Ultisols developed over a Precambrian metamorphic formation called the "Bonidoro series" and composed of schist and sandstone, sporadically traversed by veins of pegmatite, aplite, and quartz (Bonal et al., 2008). The forest around the tower is characteristic of a pristine tropical forest with both high tree density $\left(\sim 620\right.$ trees with a dbh $\left.>10 \mathrm{~cm} \mathrm{ha}^{-1}\right)$ and species richness $\left(\sim 140\right.$ species ha $\left.{ }^{-1}\right)$. The climate is highly seasonal due to the north-south movement of the Inter-Tropical Convergence Zone. The wet season, characterized by heavy rain events, lasts for 8 months (December-July) and alternates with a 4-month dry period (August-November) during which precipitation is typically lower than $100 \mathrm{~mm} \mathrm{month}^{-1}$. For the period 2004-2015, annual rainfall quantities were on average $3103 \mathrm{~mm} \mathrm{yr}^{-1}$, relative extractable water (an index of soil water availability; Wagner et al., 2011) varied from 0.93 in the wet season to 0.46 in the dry season, and soil temperature was on average $25.1^{\circ} \mathrm{C}$ with little seasonal nor diurnal variation (Aguilos et al., 2018).

\subsection{Automated sampling system}

A schematic view of the automatic sampling system is shown in Fig. 1a. The system consisted of four main components: 16 automated long-term chambers (8100-104, LI-COR Biosciences), a multiplexer to link one chamber at a time to the gas analyzers (LI-8150, LI-COR Biosciences), an infrared gas analyzer (IRGA) to measure $\mathrm{CO}_{2}$ concentrations (LI8100A, LI-COR Biosciences), and a cavity ring-down spectroscopy (CRDS) instrument to measure $\mathrm{CH}_{4}$ and $\mathrm{N}_{2} \mathrm{O}$ concentrations (G2308, Picarro) that was fitted with an external recirculation pump (A0702, Picarro). Both the IRGA and CRDS systems were necessary to measure all three GHG concentrations due to the different abundances and flux rates of $\mathrm{CO}_{2}, \mathrm{CH}_{4}$, and $\mathrm{N}_{2} \mathrm{O}$. The IRGA methodology is accurate and precise enough to detect small $\mathrm{CO}_{2}$ concentration changes at high background concentrations (approximately 
400 ppmv; parts per million in volume units). However, the detection of small changes in $\mathrm{CH}_{4}$ and $\mathrm{N}_{2} \mathrm{O}$ concentrations, even at their low background atmospheric concentrations on the order of $2000 \mathrm{ppbv}$ (ppbv; parts per billion in volume units) and $300 \mathrm{ppbv}$, respectively, requires higher accuracy and precision levels that can be detected with the CRDS.

Power supply was delivered through a $12 \mathrm{kVa}$ generator (Perkins STORM15) fitted with batteries located $400 \mathrm{~m}$ away from the instruments. Both the $\mathrm{CO}_{2}$ analyzer control unit and the multiplexer (LI-COR) had their own weather-proof casing, requiring no additional protection in the field. Nonetheless, in consideration of the high precipitation at the site, these devices were placed under a wooden shelter for added protection. The $\mathrm{CH}_{4}$ and $\mathrm{N}_{2} \mathrm{O}$ analyzer (Picarro), its external pump, and a computer monitor were housed in a waterproof shelter that was specifically designed to host them (Fig. 1c). The LI-8100 and the G2308 computers were connected through an ethernet connection to ensure time synchronization. The 16 automated soil chambers (8100-104, LI-COR Biosciences) were installed in a grid in the forest (Fig. 1b) covering in total an area of approximately $300 \mathrm{~m}^{2}(15 \mathrm{~m} \times 20 \mathrm{~m})$. Each chamber was only closed during individual chamber measurement periods and was fully open when not sampling. The PVC collars that were provided with the 8100-104 automatic chambers were inserted in the soil 1 month prior to the first measurement $(20.3 \mathrm{~cm}$ inner diameter and $21.3 \mathrm{~cm}$ outer diameter; enclosed soil area $\sim 318 \mathrm{~cm}^{2}$; insertion depth $\sim 7 \mathrm{~cm}$; offset $\sim 4 \mathrm{~cm}$; green PVC). When the chambers close, they are automatically lowered so that they cover each soil collar and ensure a fully sealed chamber. The chamber lid does not directly rest on the collar rim, but on a metal plate surrounding the collar, leaving the collar undisturbed and minimizing lateral leaks (Hupp et al., 2009).

The 16 chambers were connected via $15 \mathrm{~m}$ Bev-A-Line tubing ( $8 \mathrm{~mm}$ inner diameter) with the multiplexer (LI-8150), which allows for switching among each of the 16 chambers in any given sequence. Soil temperature $(0-10 \mathrm{~cm})$ was monitored with 8100-201 $\Omega$ thermistor probes (Omega Engineering Inc., Stamford, CT, USA), and soil volumetric water content $(0-10 \mathrm{~cm})$ was monitored with $8100-202 \mathrm{ECH}_{2} \mathrm{O}$ model EC-5 soil moisture sensors (Decagon Devices Inc., Pullman, WA, USA). Soil temperature and soil volumetric water content sensors were directly connected to the chambers and recorded by the LI-COR system using the same time step.

Each chamber was purged for $15 \mathrm{~s}$ prior to each measurement and $45 \mathrm{~s}$ after each measurement in order to flush the lines and restore background gas levels in the system. The flow rate during the purging and the measurements was $\sim 2.8 \mathrm{~L} \mathrm{~min}^{-1}$ between the LI-8150 and the chambers, which ensures sufficient air mixing in the chamber headspace during the measurements (Görres et al., 2016). Flow rates in the subsampling lines (LI-8100 and Picarro) were lower and set between 1.5 and $1.7 \mathrm{~L} \mathrm{~min}^{-1}$ as recommended by the manufacturers. The LI-8100 software provided the rate of $\mathrm{CO}_{2}$ concentration increase in the chamber, which was used to quantify the flux of $\mathrm{CO}_{2}$ from the soil surface into the atmosphere (taking into account the enclosed soil surface area and the total system volume). A subsampling loop was inserted after the analyzer (LI-8100A) and before the multiplexer (LI-8150) to pull the air sample through the Picarro G2308 CRDS analyzer for the determination of $\mathrm{CH}_{4}$ and $\mathrm{N}_{2} \mathrm{O}$ concentrations and flux estimations, before going back to the chamber (Fig. 1a). All three gas concentrations were recorded every second over the sampling periods.

\subsection{Flux calculations}

All flux estimations were carried out using commercially available SoilFluxPro software (LI-COR Biosciences). An R script (Supplement) was created to merge all the Picarro files from a given week in order to import them into the SoilFluxPro software. The Picarro creates one file per hour and when Picarro files are not merged, SoilFluxPro software is not able to deal with measurements overlapping between two distinct Picarro files (e.g., when a single measurement is performed from 09:50 to 10:15 UTC-3), leading to incorrect estimation of $\mathrm{CH}_{4}$ and $\mathrm{N}_{2} \mathrm{O}$ fluxes. To avoid underestimation of fluxes (Fig. $\mathrm{S} 1$ in the Supplement), $\mathrm{CO}_{2}, \mathrm{CH}_{4}$, and $\mathrm{N}_{2} \mathrm{O}$ fluxes were measured as exponential fit of gas concentration with time using SoilFluxPro software and include a $60 \mathrm{~s}$ dead band to account for soil surface pressure disturbances due to the closing of the chamber.

\subsection{Minimum detectable fluxes}

The minimum detectable flux (MDF) for each gas was estimated by using a metric originally developed by Christiansen et al. (2015), which was modified by Nickerson (2016) to make it more suitable for high-frequency measurements (Christiansen et al., 2015; Nickerson, 2016):

$\mathrm{MDF}=\left(\frac{A_{\mathrm{a}}}{t_{\mathrm{c}} \sqrt{n}}\right)\left(\frac{\mathrm{VP}}{\mathrm{SRT}}\right)$,

where $A_{\mathrm{a}}$ is the analytical accuracy of the analyzer ( $25 \mathrm{ppb}$ for $\mathrm{N}_{2} \mathrm{O}$ and $10 \mathrm{ppb}$ for $\mathrm{CH}_{4}$ with the Picarro G2308 and $600 \mathrm{ppb}$ for $\mathrm{CO}_{2}$ with the LI-8100, recorded from the technical data sheets of the analyzers), $t_{\mathrm{c}}$ is the closure time of the chamber in seconds, $n$ is the number of points that are available to compute the flux (i.e., $t_{\mathrm{c}}$ divided by the sampling periodicity, every $1 \mathrm{~s}$ in this study), $V$ is the chamber volume $\left(0.0040761 \mathrm{~m}^{3}\right), P$ is the atmospheric pressure (101325 Pa), $S$ is the chamber surface area $\left(0.03178 \mathrm{~m}^{2}\right), R$ is the ideal gas constant $\left(8.314 \mathrm{~m}^{3} \mathrm{~Pa} \mathrm{~K}^{-1} \mathrm{~mol}^{-1}\right)$, and $T$ is the ambient temperature $(298.15 \mathrm{~K})$. We computed the MDF of each gas for closure times from 2 to $30 \mathrm{~min}$ in order to select the optimal chamber closure time for each gas in our integrated system (Table 1). 

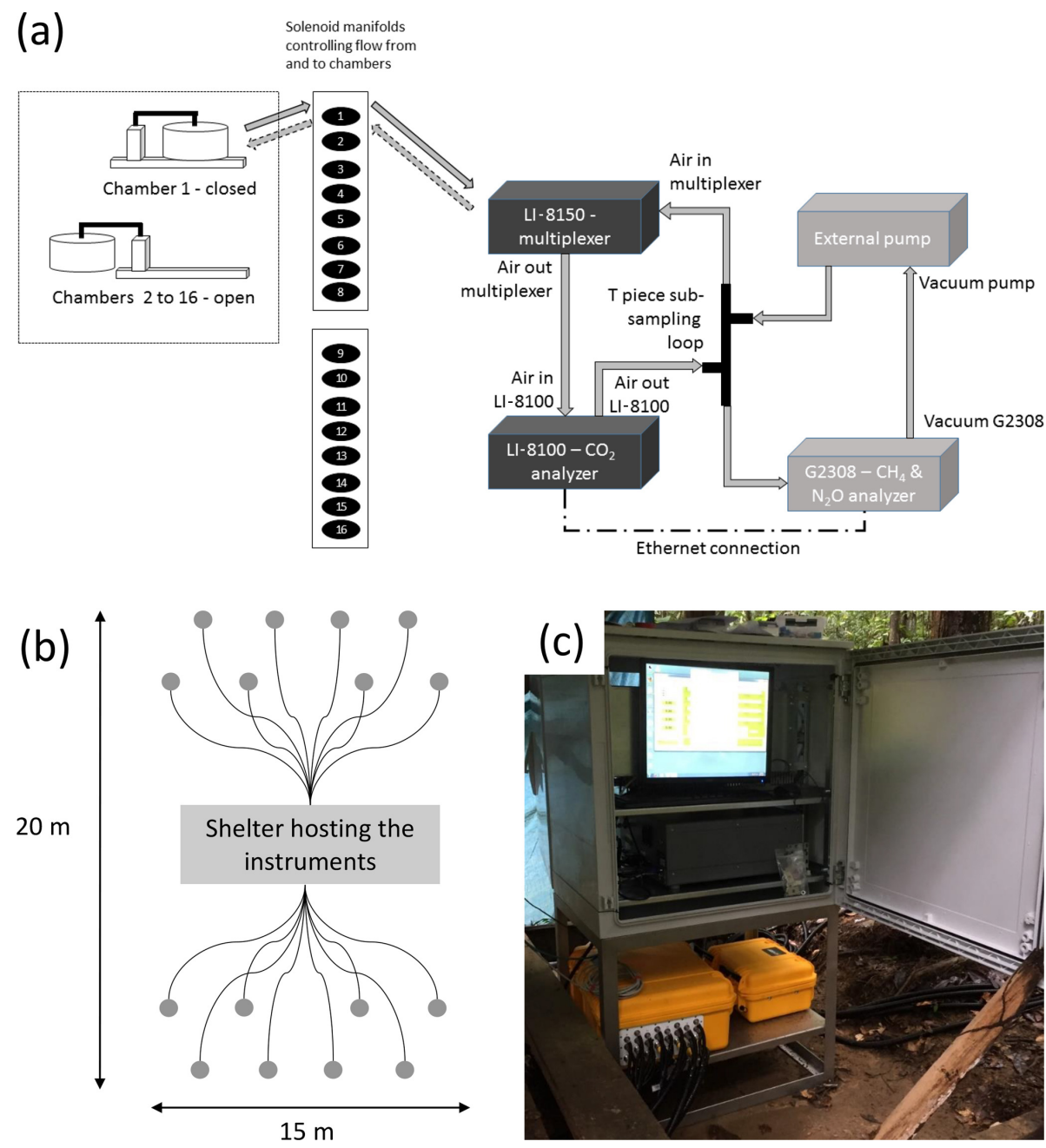

Figure 1. Experimental design. (a) Schematic view of the installation composed of four main components: 16 automated long-term chambers (8100-104, LI-COR Biosciences), a multiplexer to link one of these chambers to the gas analyzers (LI-8150, LI-COR Biosciences), an infrared gas analyzer (IRGA) to measure $\mathrm{CO}_{2}$ concentrations (LI-8100A, LI-COR Biosciences), and a cavity ring-down spectroscopy (CRDS) instrument to measure $\mathrm{CH}_{4}$ and $\mathrm{N}_{2} \mathrm{O}$ concentrations (G2308, Picarro) that was fitted with an external pump. (b) Schematic representation of the grid with the shelter housing the equipment in the middle and the 16 chambers (grey dots) linked to the LI- 8150 multiplexer with $15 \mathrm{~m}$ cables (black lines). (c) Picture of the instruments in the field.

Table 1. Minimum detectable fluxes (MDFs) for each gas and for closure times from 2 to $30 \mathrm{~min}$. The two closure times that were used in this study ( 2 and $25 \mathrm{~min}$ ) are highlighted in bold.

\begin{tabular}{lrrr}
\hline $\begin{array}{l}\text { Closure } \\
\text { time } \\
\text { (minutes) }\end{array}$ & $\begin{array}{r}\mathrm{N}_{2} \mathrm{O} \\
\left(\mathrm{nmol} \mathrm{m}^{-2} \mathrm{~s}^{-1}\right)\end{array}$ & $\begin{array}{r}\mathrm{CH}_{4} \\
\left(\mathrm{nmol} \mathrm{m}^{-2} \mathrm{~s}^{-1}\right)\end{array}$ & $\begin{array}{r}\mathrm{CO}_{2} \\
\left(\mathrm{nmol} \mathrm{m}^{-2} \mathrm{~s}^{-1}\right)\end{array}$ \\
\hline $\mathbf{2}$ & & & \\
5 & $\mathbf{0 . 1 0 0}$ & $\mathbf{0 . 0 4 0}$ & $\mathbf{2 . 3 9 3}$ \\
10 & 0.025 & 0.010 & 0.605 \\
15 & 0.009 & 0.004 & 0.214 \\
20 & 0.005 & 0.002 & 0.117 \\
$\mathbf{2 5}$ & 0.003 & 0.001 & 0.076 \\
30 & $\mathbf{0 . 0 0 2}$ & $\mathbf{0 . 0 0 1}$ & $\mathbf{0 . 0 5 4}$ \\
\hline
\end{tabular}

\subsection{Closure time}

Selecting the best length of time for soil GHG measurements and accurate flux calculation in an integrated $\mathrm{CO}_{2}, \mathrm{CH}_{4}$, and $\mathrm{N}_{2} \mathrm{O}$ automated measurement system requires careful consideration. At low fluxes, longer measurement periods are needed to reach reliable measurements of real concentration changes, while at high fluxes possible storage and saturation effects in the chamber headspace might result in nonlinear concentration increases and thereby underestimated fluxes if fluxes are calculated linearly. In order to maximize the detectable percentage of fluxes for $\mathrm{N}_{2} \mathrm{O}$ and $\mathrm{CH}_{4}$ without impeding spatial coverage and temporal resolution, we built a combined program with two different closure times. Each week, 4 out of 16 chambers were programmed to stay closed 
for a longer measurement period to ensure a reliable estimation of low fluxes while the other 12 chambers were programmed to stay closed for a shorter period to capture diel variation and detect high fluxes. For the short closure time (SHORT hereafter), we used a 2 min measurement period because (1) this is a standard closure time for soil $\mathrm{CO}_{2}$ flux calculations (Janssens et al., 2000), (2) MDF for $\mathrm{CO}_{2}$ flux is typically low (Epron et al., 2006; Bonal et al., 2008; Bréchet et al., 2009; Courtois et al., 2018), and (3) corresponding MDFs of $\mathrm{CH}_{4}\left(0.04 \mathrm{nmol} \mathrm{m}^{-2} \mathrm{~s}^{-1}\right)$ and $\mathrm{N}_{2} \mathrm{O}\left(0.1 \mathrm{nmol} \mathrm{m}^{-2} \mathrm{~s}^{-1}\right)$ are compatible with the detection of emission or consumption peaks of these two gases in this region (Courtois et al., 2018; Petitjean et al., 2015). For the long closure time (LONG hereafter), we decided to use a 25 min measurement period in order to optimize the trade-off between a reliable estimation of low $\mathrm{N}_{2} \mathrm{O}$ fluxes (Table 1) and a program length that allows for a sufficient number of flux measurements per chamber and per day.

We therefore programmed the multiplexer for $2.5 \mathrm{~h}$ cycles (9-10 measurements per chamber per day), which included four chambers with LONG measurements and 12 chambers with SHORT measurements. Each week, the program was modified manually so that the four LONG measurements were rotated across the chambers. Each chamber was therefore measured with the LONG closure time for one 7-consecutive-day period per month (4 weeks).

\subsection{System maintenance and data processing}

The automated sampling system was installed on 1 June 2016 and operated until 29 September 2016 (4 months), totaling 17592 individual measurements for each gas (4098 with LONG closure time and 13494 with SHORT closure time). Coarse wood debris were removed weekly but small litter, such as leaves, fruits, and twigs, was left in the collar area. Every week, living plants growing inside the collars, and the dead leaves on the chambers, were carefully removed by hand. The $R^{2}$ value of the exponential increase in $\mathrm{CO}_{2}$ over 2 min was used as an indicator that the system was functioning correctly and not impeded by debris (Görres et al., 2016; Savage et al., 2014). When the $R^{2}$ of the regression between time and $\mathrm{CO}_{2}$ concentration was lower than 0.9 , we considered this to be an indication that there may have been an issue with the chamber closing and sealing correctly and removed the flux measurement for all three gases from our analysis.

For $\mathrm{CO}_{2}$, we observed a strong concentration saturation effect when using the LONG closure time ( $25 \mathrm{~min}$ ), leading to an underestimation of fluxes (Fig. 2). All $\mathrm{CO}_{2}$ flux estimates were therefore based on 2 min regressions only, using either full concentration measurements of the SHORT closure time or the first $2 \mathrm{~min}$ of the LONG closure time. Following recommendations (Rubio and Detto, 2017), we removed anomalous values, i.e., $\mathrm{CO}_{2}$ fluxes estimation with a difference greater than $5 \mu \mathrm{mol} \mathrm{m}{ }^{-2} \mathrm{~s}^{-1}$ with adjacent measurements or lower than $0 \mu \mathrm{mol} \mathrm{m}{ }^{-2} \mathrm{~s}^{-1}$. For $\mathrm{CH}_{4}$, we ob- served only a slight saturation effect when using the LONG closure time (Fig. 2). Variation in the flux calculations did not differ between the SHORT and LONG chamber closure measurements. $\mathrm{N}_{2} \mathrm{O}$ flux calculations were much more variable when measuring with the SHORT closure time compared to the LONG closure time (Fig. 2). Even if fluxes were above the detection limit, the low fluxes estimated with the SHORT closure time were not reliable as shown by the low correlation in Fig. 2. For both $\mathrm{CH}_{4}$ and $\mathrm{N}_{2} \mathrm{O}$, we therefore decided to apply the following quality check procedure and to discard (1) all fluxes that were not complying with MDF criterion, (2) all fluxes estimated with the SHORT closure time with a $R^{2}$ lower than 0.8 (Savage et al., 2014), and (3) all anomalous values (difference greater than $5 \mathrm{nmol} \mathrm{m}^{-2} \mathrm{~s}^{-1}$ with adjacent measurements).

\section{Results and discussions}

A cleaning frequency of once a week was necessary and sufficient to remove falling leaves and branches from the automatic chamber system, prevent leaks, and generate a continuous dataset of soil GHG fluxes from this tropical forest. Temperature variations are typically small below the canopy due to the shadowing by dense canopy crown and microclimatic conditions. During the study period, temperature at $2 \mathrm{~m}$ in height varied from $22{ }^{\circ} \mathrm{C}$ in the night to $28^{\circ} \mathrm{C}$ during the day. The presence of water condensation inside the tubing lines was carefully checked every week and never occurred during the study period. The automatic chamber system worked well most of the time, but some data gaps did exist. Over the 17592 individual flux estimations, $343(1.9 \%)$ had to be discarded because of (1) problems in the connection between the chamber and the multiplexer (154 measurements, $0.9 \%$ of data points) and (2) imperfect chamber closing, which was detected by an insufficient increase in $\mathrm{CO}_{2}$ (189 measurements, $1 \%$ of data points).

\section{1 $\mathrm{CO}_{2}$ fluxes}

In addition to the 343 fluxes that were removed after the first steps of the quality check procedure, $758 \mathrm{CO}_{2}$ flux estimations were also considered to be anomalous because the difference with adjacent measurements were either greater than $5 \mu \mathrm{mol} \mathrm{m}{ }^{-2} \mathrm{~s}^{-1}$ (758 measurements, i.e., $4.3 \%$ ) or lower than $0 \mu \mathrm{mol} \mathrm{m}^{-2} \mathrm{~s}^{-1}$ (14 measurements). In total, $16477 \mathrm{CO}_{2}$ fluxes over $17592(93.6 \%)$ could be used over the 4-month period. $\mathrm{CO}_{2}$ fluxes were on average $8.1 \pm 1.6 \mu \mathrm{mol} \mathrm{m}^{-2} \mathrm{~s}^{-1}$ (Table 2), which would correspond to a mean annual soil $\mathrm{CO}_{2}$ efflux of $3050 \mathrm{gC} \mathrm{m}^{-2} \mathrm{yr}^{-1}$, which falls into the upper range of the extensive review of mean annual soil $\mathrm{CO}_{2}$ efflux estimations in tropical forest provided recently by Rubio and Detto (2017). Nonetheless, our study period (June-September) only covered the end of the wet season and more data are needed to make this 
(a)

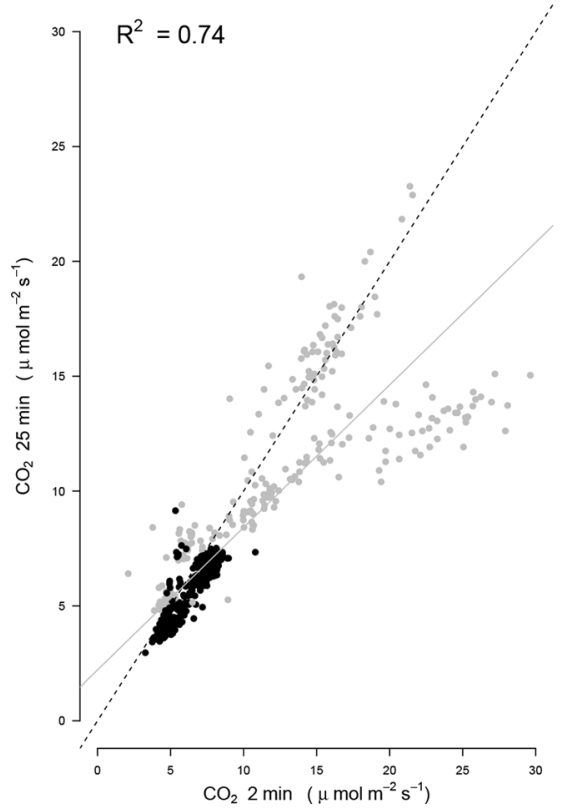

(b)

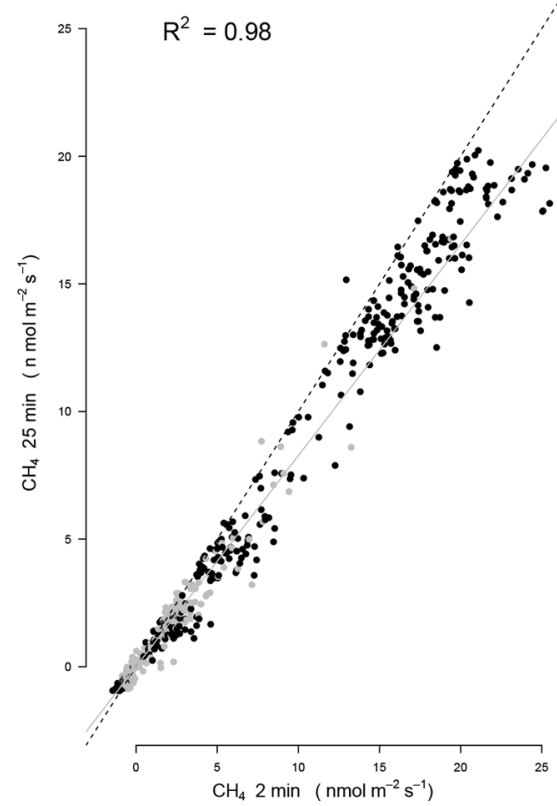

(c)

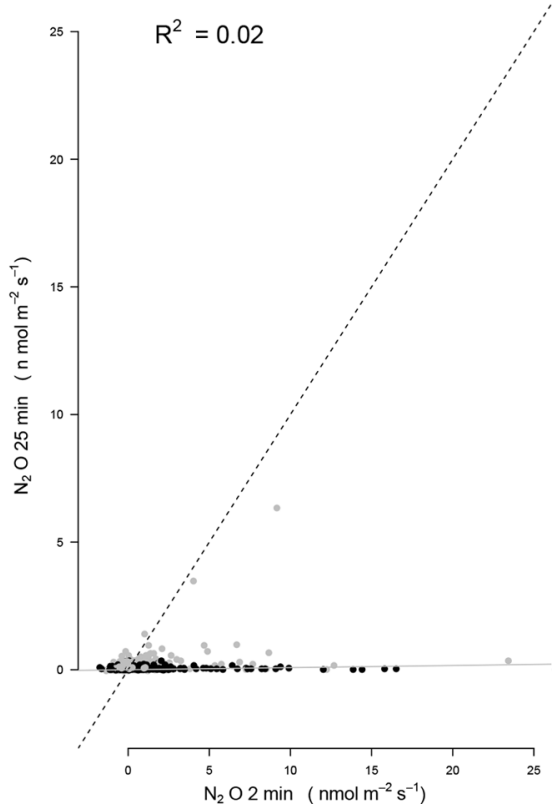

Figure 2. Comparison of 2 and 25 min estimations for (a) $\mathrm{CO}_{2}$, (b) $\mathrm{CH}_{4}$, and (c) $\mathrm{N}_{2} \mathrm{O}$ fluxes. For this, we used measurements made over $25 \mathrm{~min}$ and recomputed the flux with the first 2 min for 2 weeks (from 2 to 9 August in black and from 16 to 25 August in grey) covering the whole range of fluxes during the study period. All fluxes were computed using exponential fit. The dashed line represents the $1: 1$ line while the solid grey line represents the linear regression between 2 and 25 min estimations $\left(R^{2}\right.$ values of these regressions are indicated in each panel).

Table 2. Mean, standard deviation (SD), minimum (Min), and maximum (Max) values of each gas and each chamber over the study period. These values are computed using all flux estimations (with either SHORT or LONG closure times) remaining after quality check. The number $(N)$ of fluxes that were used is also indicated for each chamber. The last line of the table is the mean of all fluxes by chamber by gas and the min and max for all chambers by gas.

\begin{tabular}{|c|c|c|c|c|c|c|c|c|c|c|c|c|c|c|c|}
\hline & \multicolumn{5}{|c|}{$\mathrm{CO}_{2}\left(\mu \mathrm{mol} \mathrm{m}{ }^{-2} \mathrm{~s}^{-1}\right)$} & \multicolumn{5}{|c|}{$\mathrm{CH}_{4}\left(\mathrm{nmol} \mathrm{m}^{-2} \mathrm{~s}^{-1}\right)$} & \multicolumn{5}{|c|}{$\mathrm{N}_{2} \mathrm{O}\left(\mathrm{nmol} \mathrm{m}^{-2} \mathrm{~s}^{-1}\right)$} \\
\hline Chamber 1 & 7.19 & 0.93 & 2.14 & 10.81 & 940 & 10.97 & 7.73 & -2.08 & 28.79 & 840 & 0.10 & 0.12 & -0.48 & 0.70 & 284 \\
\hline Chamber 3 & 5.58 & 0.99 & 2.11 & 11.12 & 1135 & 0.35 & 2.95 & -2.48 & 22.94 & 745 & 0.03 & 0.23 & -0.61 & 2.85 & 208 \\
\hline Chamber 4 & 7.94 & 1.37 & 4.36 & 12.13 & 1154 & -1.85 & 1.23 & -3.63 & 6.09 & 1105 & 0.04 & 0.10 & -0.66 & 0.60 & 224 \\
\hline Chamber 5 & 4.14 & 0.92 & 0.53 & 10.05 & 1139 & 1.37 & 3.26 & -2.20 & 12.61 & 752 & 0.15 & 0.33 & -1.04 & 3.23 & 382 \\
\hline Chamber 8 & 7.44 & 1.19 & 2.03 & 11.02 & 1099 & 0.03 & 2.96 & -3.37 & 18.47 & 785 & 0.02 & 0.15 & -1.36 & 0.84 & 202 \\
\hline Chamber 9 & 4.25 & 1.20 & 0.44 & 11.37 & 1002 & 2.06 & 3.13 & -2.14 & 11.53 & 879 & 0.02 & 0.11 & -0.62 & 0.58 & 332 \\
\hline Chamber 10 & 5.60 & 1.30 & 0.69 & 13.13 & 1037 & 1.21 & 2.46 & -1.91 & 10.34 & 657 & 0.04 & 0.13 & -0.64 & 0.77 & 252 \\
\hline Chamber 11 & 11.97 & 2.19 & 6.84 & 18.78 & 1004 & 6.72 & 7.61 & -1.06 & 41.49 & 855 & 0.03 & 0.17 & -1.01 & 1.04 & 199 \\
\hline Chamber 12 & 9.42 & 2.70 & 3.45 & 21.54 & 968 & 1.40 & 6.68 & -3.29 & 41.94 & 891 & 0.02 & 0.09 & -0.75 & 0.30 & 204 \\
\hline Chamber 13 & 5.85 & 1.34 & 0.42 & 8.49 & 944 & 5.29 & 5.92 & -4.60 & 26.64 & 654 & 0.10 & 0.19 & -0.84 & 1.71 & 335 \\
\hline Chamber 16 & 8.06 & 1.58 & 0.42 & 29.64 & 16477 & 1.68 & 3.80 & -4.60 & 41.94 & 12985 & 0.08 & 0.23 & -1.36 & 7.93 & 3998 \\
\hline
\end{tabular}


(a)

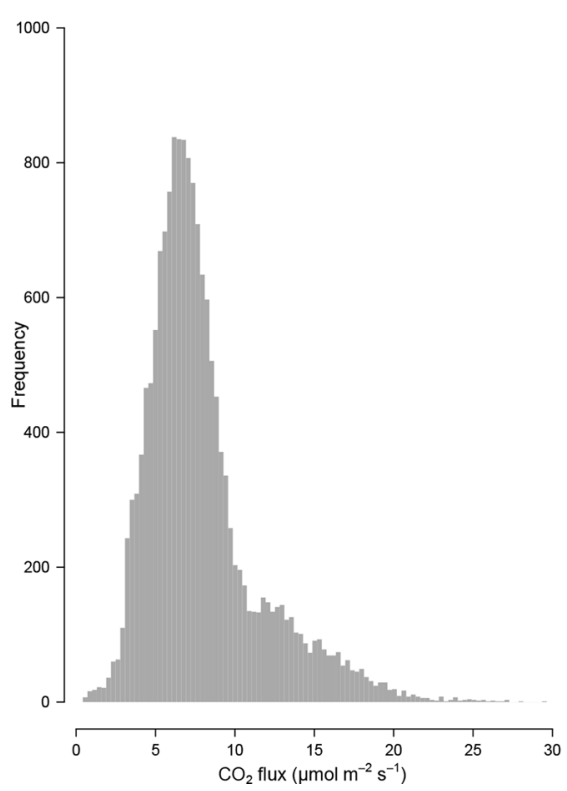

(b)

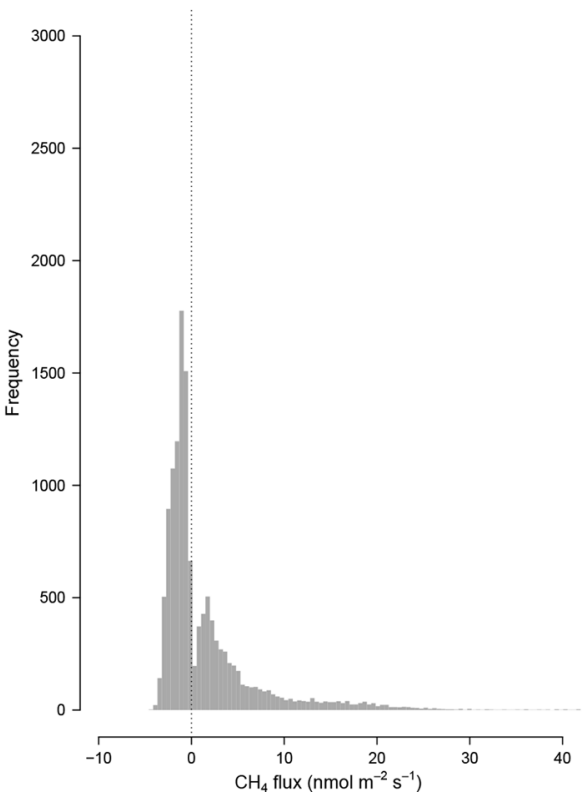

(c)

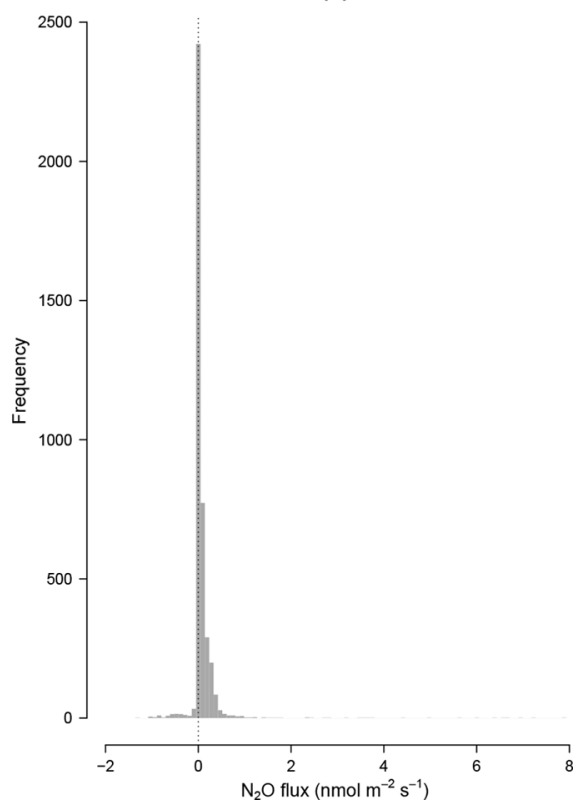

Figure 3. Distribution of fluxes: histogram of (a) $\mathrm{CO}_{2}$, (b) $\mathrm{CH}_{4}$, and (c) $\mathrm{N}_{2} \mathrm{O}$ fluxes over the study period. For (b) and (c), the dotted line represents null fluxes.

estimation more precise. All 2 min measurements of $\mathrm{CO}_{2}$ fluxes from the 4-month study period were above the MDF of $2.39 \mathrm{nmol} \mathrm{m}^{-2} \mathrm{~s}^{-1}$ for the LI-8100 analyzer (Table 1). No saturation effect was detected using the SHORT closure time, and estimation of $\mathrm{CO}_{2}$ over a shorter time period is not recommended (Davidson et al., 2002). $\mathrm{CO}_{2}$ fluxes using the LONG closure time would be underestimated due to the buildup of high $\mathrm{CO}_{2}$ concentrations due to large fluxes over this long time period (Fig. 2), and are not recommended. For small chambers like the one used in this study, we therefore conclude that a 2 min sampling time including a dead band of $60 \mathrm{~s}$ should be used for $\mathrm{CO}_{2}$ flux calculations since the MDF of this short measurement period allowed for the retention of $100 \%$ of the data. When the chambers stay closed longer for accurate detection of $\mathrm{N}_{2} \mathrm{O}$ and $\mathrm{CH}_{4}$ fluxes, only the first 2 min of data should be used for $\mathrm{CO}_{2}$ flux calculations.

The use of 16 automated flux chambers allowed for the capture of spatial and temporal variability in soil respiration. Over this 4-month period, corresponding to the end of the wet season in French Guiana, temporal variability remained low (Fig. 4). This dataset is therefore not long enough to detect the seasonal variation in soil respiration that was highlighted in previous study (Rowland et al., 2014; Rubio and Detto, 2017). We did found that soil respiration tended to decrease in very humid soils (Fig. S2 in the Supplement) as highlighted previously at the same site (Rowland et al., 2014) but more data are needed to precisely disentangle the importance of seasonal and diurnal variability from the responses to environmental triggers of soil respiration. Nonetheless, even during this relatively short period, our data clearly demonstrated a strong spatial variability in soil respiration, even at a low spatial scale (Fig. 5, Table 2), with some local spots clearly displaying stronger values of soil respiration during the study period.

\section{2 $\mathrm{CH}_{4}$ fluxes}

In addition to the 343 fluxes that were removed after the first steps of the quality check procedure, $\mathrm{CH}_{4}$ flux estimations were also discarded because of (1) problems with Picarro files (12 measurements), (2) application of the MDF criterion (137 measurements), (3) application of the $R^{2}$ criterion for SHORT closure time (3751 measurements, i.e., $28 \%$ of the SHORT measurements), and (4) detection of anomalous values (364 measurements). In total, $12985 \mathrm{CH}_{4}$ fluxes over $17592(73.8 \%)$ could be used over the 4-month period. No saturation effect was detected using the LONG closure time and fluxes estimated with the SHORT closure time were very well-correlated to fluxes using the LONG closure time, even for small fluxes (Fig. 2). Totals of $68.4 \%$ and $98.2 \%$ of fluxes measured with the SHORT and LONG closure times, respectively, were retained in our quality control data processing over the 4-month study period. These measurement periods, therefore, allowed for the retention of a large majority of $\mathrm{CH}_{4}$ emission or consumption fluxes in our data analysis.

$\mathrm{CH}_{4}$ fluxes were on average $1.7 \pm 3.8 \mathrm{nmol} \mathrm{m}^{-2} \mathrm{~s}^{-1}$ with a high variability among chambers (Table 2 ) but the frequency of negative $\mathrm{CH}_{4}$ fluxes (consumption, $59 \%$ of fluxes) was greater than for positive fluxes (emission, $41 \%$ of fluxes) 

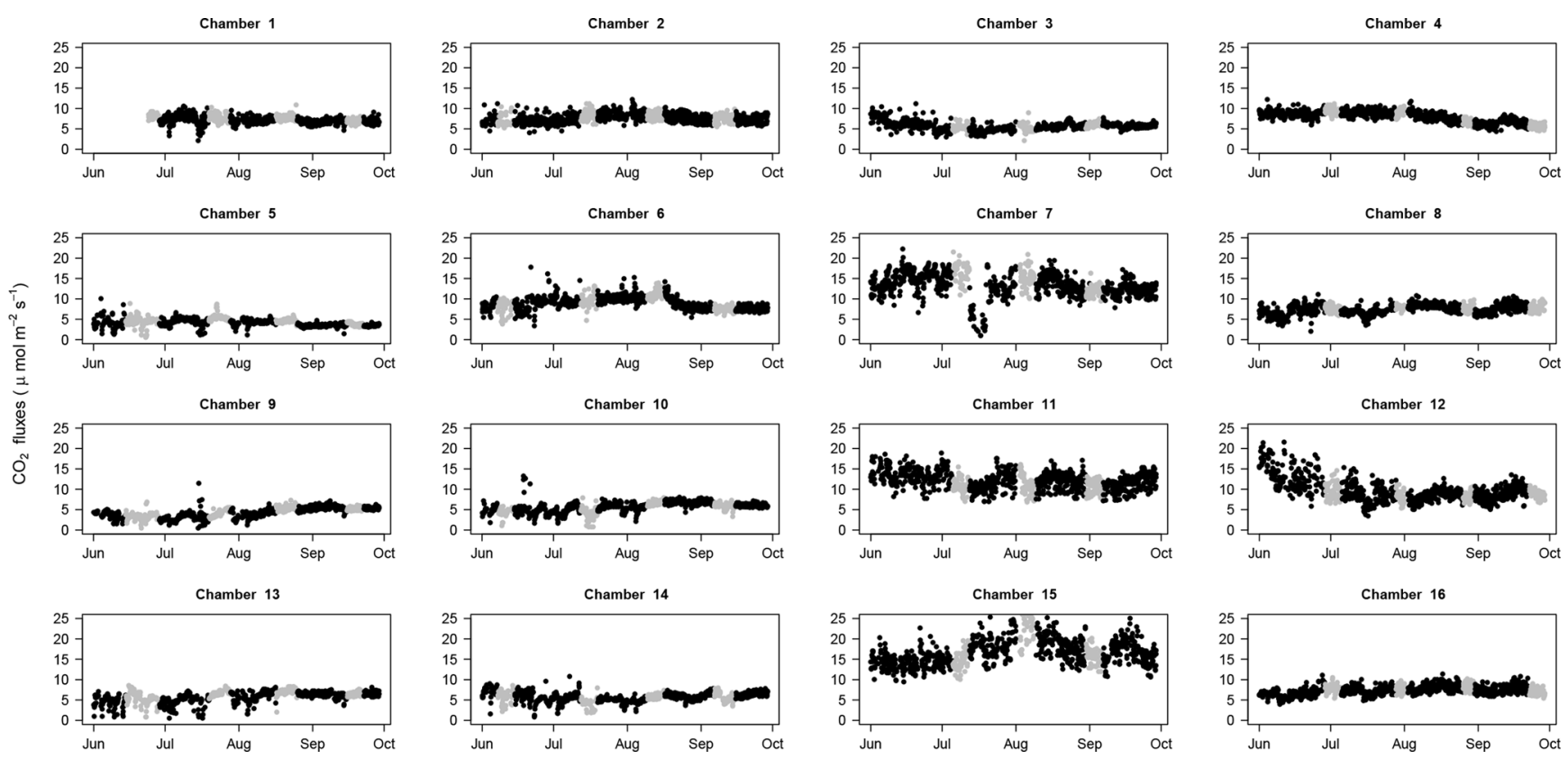

Figure 4. $\mathrm{CO}_{2}$ fluxes through time: $\mathrm{CO}_{2}$ fluxes for each chamber (1 to 16) over the study period with fluxes estimated with a SHORT ( 2 min) closure time in black and fluxes estimated with the first $2 \mathrm{~min}$ of the LONG ( $25 \mathrm{~min}$ ) closure time in grey. All panels have the same limits on the $y$ axis (from 0 to $25 \mu \mathrm{mol} \mathrm{m}^{-2} \mathrm{~s}^{-1}$ ).

(a)

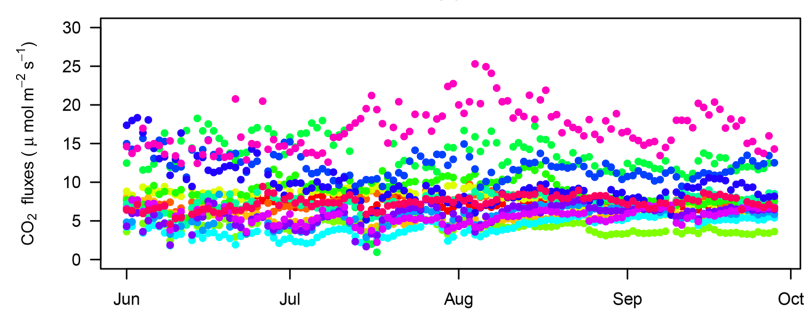

(b)

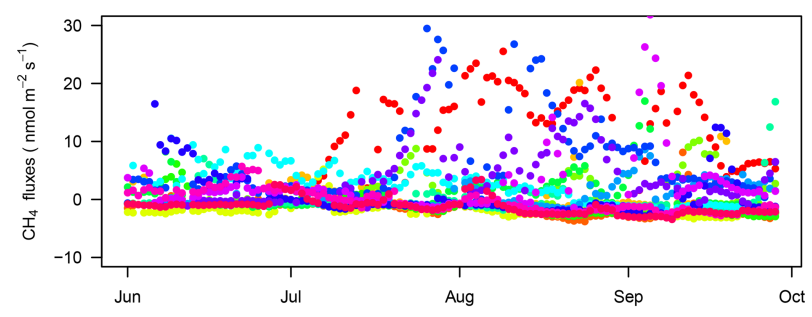

(c)

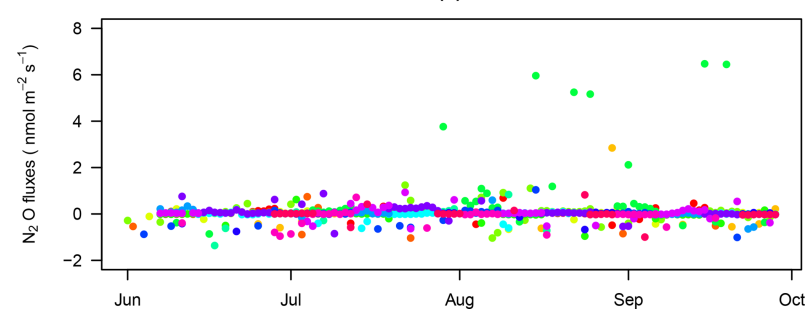

Figure 5. Mean values per day for (a) $\mathrm{CO}_{2}$, (b) $\mathrm{CH}_{4}$, and (c) $\mathrm{N}_{2} \mathrm{O}$ fluxes over the study period. Each chamber is represented by a distinct color. during this period (Fig. 3). Most of the time, soils were either consuming or emitting small amounts of $\mathrm{CH}_{4}$, but large transient emission peaks were periodically detected at individual chamber locations during the study period (Fig. 6). Tropical soils are generally considered to be a sink at a yearly basis (Dutaur and Verchot, 2007) but it is known that these soils can shift from a source in the wet season to a sink in the dry season (Courtois et al., 2018; Davidson et al., 2008; Teh et al., 2014). No clear temporal trend could be detected during the study period and there was a slight correlation of $\mathrm{CH}_{4}$ fluxes with surface soil humidity (higher fluxes at intermediate soil humidity, Fig. S2). Longer time series covering at least a full year are needed to explore the seasonal and diurnal variability in fluxes. As highlighted previously in French Guiana (Courtois et al., 2018), spatial variability in $\mathrm{CH}_{4}$ emission was high, even at a small spatial scale (Figs. 5, 6). Interestingly, some spots clearly displayed high $\mathrm{CH}_{4}$ emissions during the whole study period (Figs. 5, 6).

\section{3 $\quad \mathrm{N}_{2} \mathrm{O}$ fluxes}

In addition to the 343 fluxes that were removed after the first steps of the quality check procedure, $\mathrm{N}_{2} \mathrm{O}$ flux estimations were also discarded because of (1) problems with Picarro files (12 measurements), (2) application of the MDF criterion (1594 measurements), (3) application of the $R^{2}$ criterion for SHORT closure time (11643 measurements, i.e., $28 \%$ of the SHORT measurements), and (4) detection of anomalous values (364 measurements). In total, $3998 \mathrm{~N}_{2} \mathrm{O}$ fluxes over 17592 measurements $(22.7 \%, 140$ measurements with 

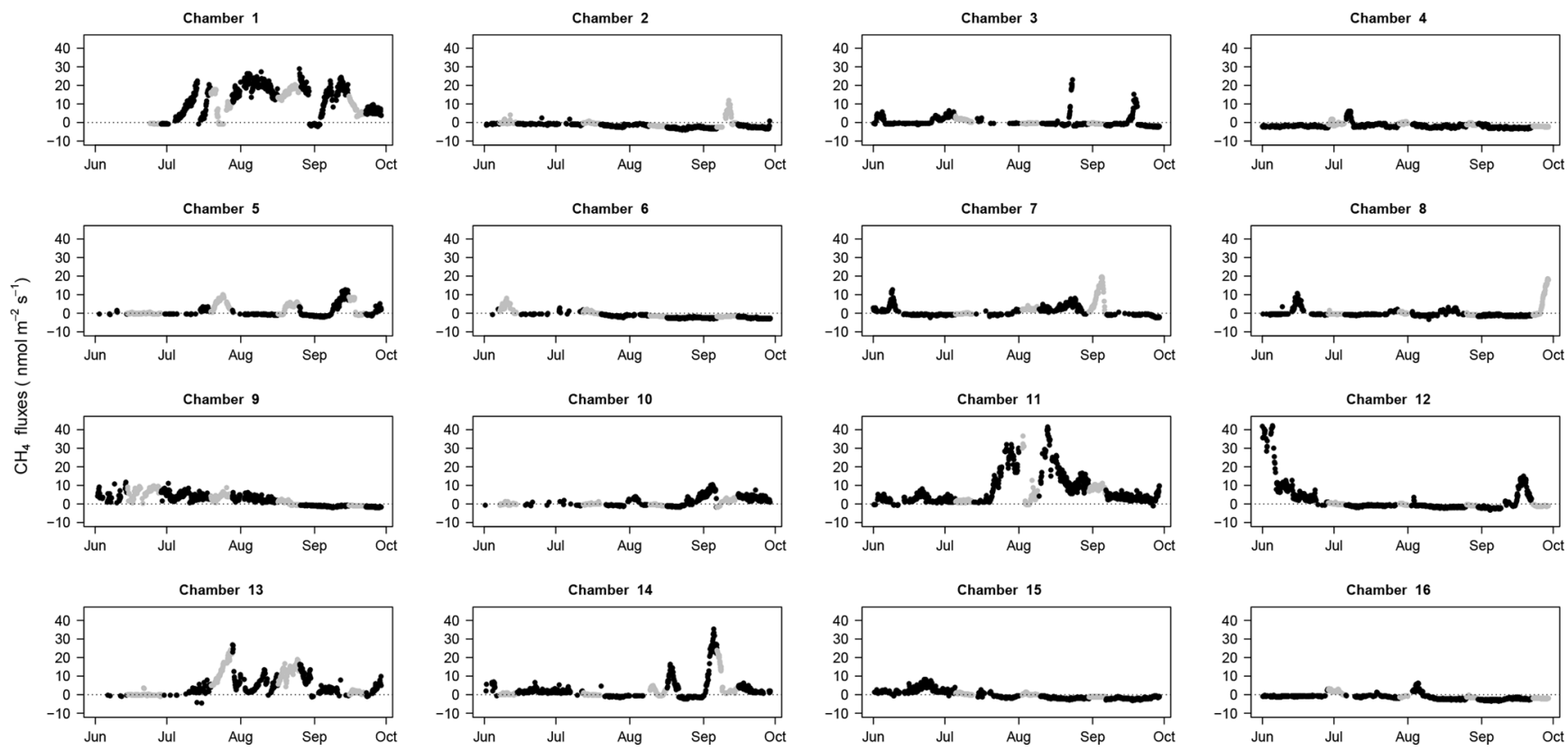

Figure 6. $\mathrm{CH}_{4}$ fluxes through time: $\mathrm{CH}_{4}$ fluxes for each chamber (1 to 16) over the study period with fluxes estimated with a SHORT ( 2 min) closure time in black and fluxes estimated with a LONG $(25 \mathrm{~min})$ closure time in grey. The dotted line displays the zero flux line. All panels have the same limits on the $y$ axis (from -5 to $30 \mathrm{nmol} \mathrm{m}^{-2} \mathrm{~s}^{-1}$ ).
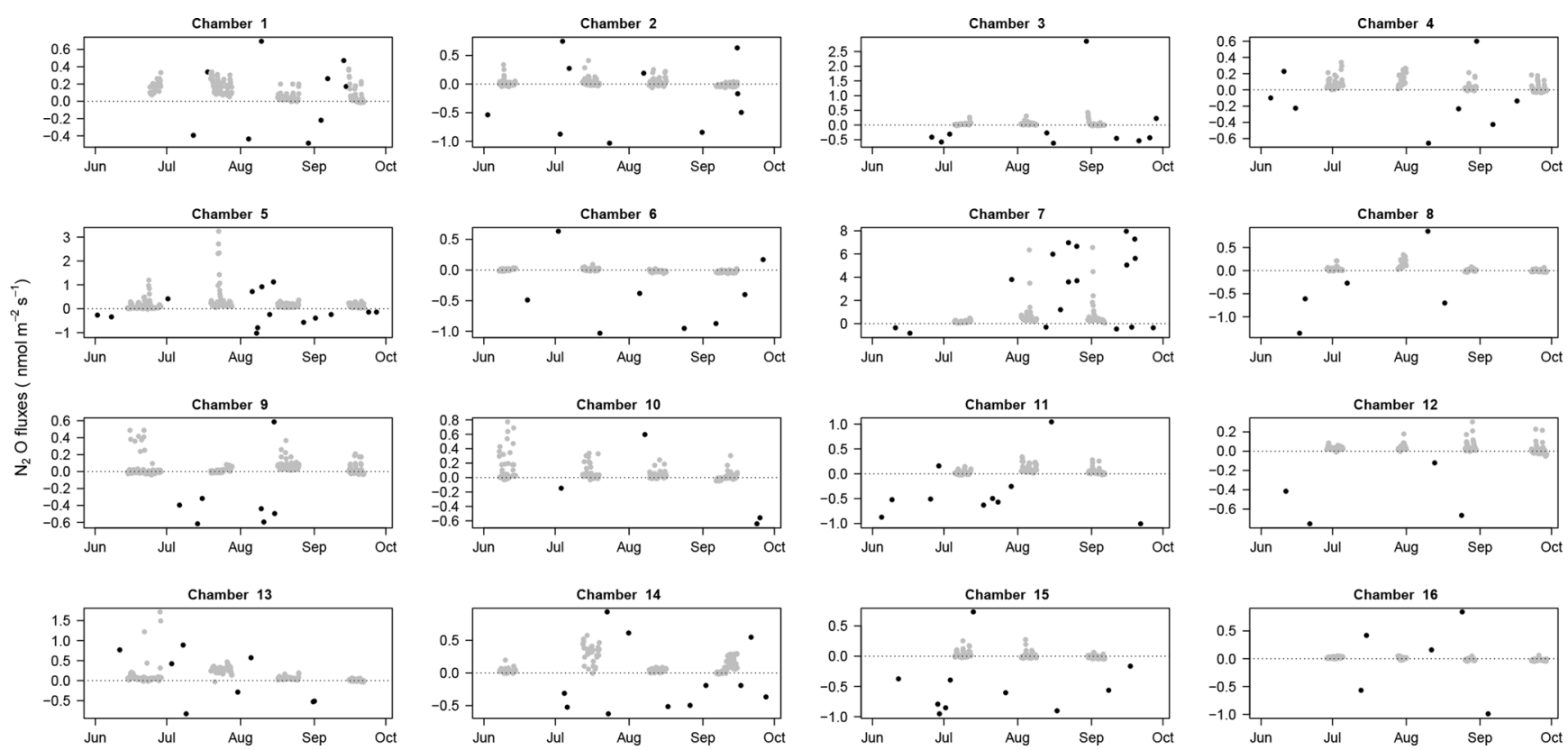

Figure 7. $\mathrm{N}_{2} \mathrm{O}$ fluxes through time: $\mathrm{N}_{2} \mathrm{O}$ fluxes for each chamber (1 to 16) over the study period with fluxes estimated with the SHORT ( $2 \mathrm{~min}$ ) closure time in black and fluxes estimated with the LONG ( $25 \mathrm{~min}$ ) closure time in grey. The dotted line displays the zero flux line. Due to the high differences among chambers, each panel has a specific limit on the $y$ axis. 
the SHORT and 3858 measurements with the LONG closure time) could be used over the 4-month period. A total of $94.1 \%$ of fluxes measured with the LONG closure times were retained after our quality control data processing over the 4-month study period. When measured over 25 min, $\mathrm{N}_{2} \mathrm{O}$ fluxes at our site could therefore be considered reliable. Using the SHORT closure time, most flux estimations had to be discarded because they led to unreliable flux estimations (Fig. 2). Nonetheless, the SHORT closure time still allowed the detection of high $\mathrm{N}_{2} \mathrm{O}$ emission or consumption events than were detected during the study period (Figs. 5 and 7).

$\mathrm{N}_{2} \mathrm{O}$ fluxes were on average $0.1 \pm 0.2 \mathrm{nmol} \mathrm{m}^{-2} \mathrm{~s}^{-1}$ with a high variability among chambers (Table 2). At the same chamber, $\mathrm{N}_{2} \mathrm{O}$ flux can shift from consumption to emission with $28 \%$ of fluxes indicating a sink and $72 \%$ a source for $\mathrm{N}_{2} \mathrm{O}$ (Fig. 3). The high variability in $\mathrm{N}_{2} \mathrm{O}$ fluxes that we detected over 4 months with our automated system is in agreement with the typical high variability in $\mathrm{N}_{2} \mathrm{O}$ fluxes measured from tropical soils over space and time using static chambers (Arias-Navarro et al., 2017; Courtois et al., 2018). Moreover, $\mathrm{N}_{2} \mathrm{O}$ fluxes did not show any relationship with surface soil humidity (Fig. S2), which underlines the complexity of the biological process underlying these fluxes. In a previous study in the same environment (Courtois et al., 2018), we estimated that the minimum detectable flux using gas chromatography analysis of four discrete gas samples over $30 \mathrm{~min}$ for $\mathrm{N}_{2} \mathrm{O}$ was $\pm 8.3 \mu \mathrm{g} \mathrm{N} \mathrm{m}^{-2} \mathrm{~h}^{-1}$. MDF estimated in the present study using high-frequency measurement was $0.002 \mathrm{nmol} \mathrm{m}^{-2} \mathrm{~s}^{-1}$ or $0.2 \mu \mathrm{g} \mathrm{N} \mathrm{m}^{-2} \mathrm{~h}^{-1}$ for $\mathrm{N}_{2} \mathrm{O}$ which is therefore $\sim 40$ times lower. Such result indicates that this long-term system is well-adapted to capture and estimate the low $\mathrm{N}_{2} \mathrm{O}$ fluxes occurring in this ecosystem.

\section{Conclusions}

We demonstrated here that the combination of a commercial soil GHG chamber system - the LI-8100A Automated Soil $\mathrm{CO}_{2}$ Flux System - running in parallel with a Picarro G2308, enables the continuous long-term measurement of $\mathrm{CO}_{2}, \mathrm{CH}_{4}$, and $\mathrm{N}_{2} \mathrm{O}$ simultaneously under tropical conditions. Similar configurations have been recently implemented in temperate climate (Petrakis et al., 2017a, b), but to our knowledge, this is the first time that this experimental setup is fully described and tested under tropical field conditions for the measurement of the three soil GHG fluxes simultaneously. Additionally, our study determined the optimal chamber closure time for each GHG. The sampling system of SHORT and LONG closure times with a weekly rotation presented here has three major advantages, which ultimately can provide high confidence in the annual estimation of the full GHG budgets of tropical soils: (1) the LONG closure time allows a reliable estimation of the low $\mathrm{N}_{2} \mathrm{O}$ fluxes in this ecosystem, which was clearly not achieved using a shorter closure time; (2) the number of data points per day are sufficiently high (9 to 10 measurements per day) to capture potential diurnal variation (Nicolini et al., 2013; Rubio and Detto, 2017) in the three gases with good spatial replication (16 chambers); (3) periodic extreme events of high $\mathrm{N}_{2} \mathrm{O}$ fluxes can still be detected with the SHORT closure time period, which occurs at a higher frequency than the LONG closure measurements. Our study underlines the importance of appropriate closure time for each GHG gas for accurate estimation of GHG budgets. This information is crucial for the calculation of accurate soil fluxes at diurnal time steps and for the estimation of annual GHG budgets. This combination of automated closed dynamic chambers and advanced GHG analyzers makes it possible to (1) account for short-term variability in GHG fluxes while taking into account spatial variability, (2) estimate annual GHG budgets at these locations, (3) tracking the variability in GHG fluxes along hours, days, seasons, and years, and (4) study the impact of climatic change on soil GHG budgets.

Data availability. Data used in this study can be freely accessed through the Zenodo repository: https://doi.org/10.5281/zenodo. 2555299 (Courtois and Stahl, 2019).

Supplement. The supplement related to this article is available online at: https://doi.org/10.5194/bg-16-785-2019-supplement.

Author contributions. JVB and NA designed the experiment and $\mathrm{EAC}, \mathrm{CS}, \mathrm{BB}$, and DB carried it out. EAC and CS prepared the paper with contributions from all co-authors. EAC and CS contributed equally to the paper.

Competing interests. The authors declare that they have no conflict of interest.

Acknowledgements. This research was supported by the European Research Council Synergy grant ERC-2013-SyG 610028IMBALANCE-P. We thank Jan Segers for help in the initial setting of the system and Renato Winkler from Picarro and Rod Madsen and Jason Hupp from LI-COR for their help in combining the systems. We thank the staff of Paracou station, managed by UMR Ecofog (CIRAD, INRA; Kourou), which received support from "Investissement d'Avenir" grants managed by Agence Nationale de la Recherche (CEBA: ANR-10-LABX-25-01, ANAEE-France: ANR-11-INBS-0001). This study was conducted in collaboration with the Guyaflux program belonging to SOERE F-ORE-T, which is supported annually by Ecofor, Allenvi, and the French national research infrastructure, ANAEE-F. This program also received support from an "investissement d'avenir" grant from the Agence Nationale de la Recherche (CEBA, ref ANR-10LABX-25-01). Ivan August Janssens acknowledges support from Antwerp University (Methusalem funding), Nicola Arriga from ICOS-Belgium and Fonds Wetenschappelijk Onderzoek (FWO), 
and Jennifer Larned Soong from the U.S. Department of Energy under contract DE-AC02-05CH11231.

Edited by: Kees Jan van Groenigen

Reviewed by: three anonymous referees

\section{References}

Aguilos, M., Hérault, B., Burban, B., Wagner, F., and Bonal, D.: What drives long-term variations in carbon flux and balance in a tropical rainforest in French Guiana?, Agr. Forest Meteorol., 253, 114-123, 2018.

Ambus, P., Skiba, U., Drewer, J., Jones, S., Carter, M. S., Albert, K. R., and Sutton, M.: Development of an accumulation-based system for cost-effective chamber measurements of inert trace gas fluxes, Eur. J. Soil Sci., 61, 785-792, 2010.

Arias-Navarro, C., Díaz-Pinés, E., Klatt, S., Brandt, P., Rufino, M. C., Butterbach-Bahl, K., and Verchot, L.: Spatial variability of soil $\mathrm{N}_{2} \mathrm{O}$ and $\mathrm{CO}_{2}$ fluxes in different topographic positions in a tropical montane forest in Kenya, J. Geophys. Res.-Biogeo., 122, 514-527, 2017.

Bonal, D., Bosc, A., Ponton, S., Goret, J. Y., Burban, B., Gross, P., Bonnefond, J., Elbers, J., Longdoz, B., and Epron, D.: Impact of severe dry season on net ecosystem exchange in the Neotropical rainforest of French Guiana, Glob. Change Biol., 14, 1917-1933, 2008.

Bréchet, L., Ponton, S., Roy, J., Freycon, V., Coûteaux, M.-M., Bonal, D., and Epron, D.: Do tree species characteristics influence soil respiration in tropical forests? A test based on 16 tree species planted in monospecific plots, Plant Soil, 319, 235-246, 2009.

Breuer, L., Papen, H., and Butterbach-Bahl, K.: $\mathrm{N}_{2} \mathrm{O}$ emission from tropical forest soils of Australia, J. Geophys. Res.-Atmos., 105, 26353-26367, 2000.

Christiansen, J. R., Outhwaite, J., and Smukler, S. M.: Comparison of $\mathrm{CO}_{2}, \mathrm{CH}_{4}$ and $\mathrm{N}_{2} \mathrm{O}$ soil-atmosphere exchange measured in static chambers with cavity ring-down spectroscopy and gas chromatography, Agr. Forest Meteorol., 211, 48-57, 2015.

Courtois, E. A. and Stahl, C.: Dataset from: Automatic high-frequency measurements of full soil greenhouse gas fluxes in a tropical forest Biogeosciences 2019, https://doi.org/10.5281/zenodo.2555299, 2019.

Courtois, E. A., Stahl, C., Van den Berge, J., Bréchet, L., Van Langenhove, L., Richter, A., Urbina, I., Soong, J. L., Peñuelas, J., and Janssens, I. A.: Spatial variation of soil $\mathrm{CO}_{2}, \mathrm{CH}_{4}$ and $\mathrm{N}_{2} \mathrm{O}$ fluxes across topographical positions in tropical forests of the Guiana Shield, Ecosystems, 21, 1445-1458, 2018.

Davidson, E., Savage, K., Verchot, L., and Navarro, R.: Minimizing artifacts and biases in chamber-based measurements of soil respiration, Agr. Forest Meteorol., 113, 21-37, 2002.

Davidson, E. A., Nepstad, D. C., Ishida, F. Y., and Brando, P. M.: Effects of an experimental drought and recovery on soil emissions of carbon dioxide, methane, nitrous oxide, and nitric oxide in a moist tropical forest, Glob. Change Biol., 14, 2582-2590, 2008.

De Klein, C. and Harvey, M.: Nitrous oxide chamber methodology guidelines, Ministry for Primary Industries: Wellington, New Zealand, 2012.
Denmead, O.: Chamber systems for measuring nitrous oxide emission from soils in the field, Soil Sci. Soc. Am. J., 43, 89-95, 1979.

Dutaur, L. and Verchot, L. V.: A global inventory of the soil $\mathrm{CH}_{4}$ sink, Glob. Biogeochem. Cy., 21, https://doi.org/10.1029/2006GB002734, 2007.

Epron, D., Bosc, A., Bonal, D., and Freycon, V.: Spatial variation of soil respiration across a topographic gradient in a tropical rain forest in French Guiana, J. Trop. Ecol., 22, 565-574, 2006.

FAO/ISRIC/ISSS: World Reference Base for Soil Resources.FAO, ISRIC, ISSS, World Soil Resources Reports 84, Rome, 1998.

Görres, C.-M., Kammann, C., and Ceulemans, R.: Automation of soil flux chamber measurements: potentials and pitfalls, Biogeosciences, 13, 1949-1966, https://doi.org/10.5194/bg-13-19492016, 2016.

Hupp, J. R., Garcia, R. L., Madsen, R., and McDermitt, D. K.: Measurement of $\mathrm{CO}_{2}$ evolution in a multiplexed flask system, Amer. Soc. Horticultural Science, Alexandria, USA, Vol. 44, 11431143, 2009.

Janssens, I. A., Kowalski, A. S., Longdoz, B., and Ceulemans, R.: Assessing forest soil $\mathrm{CO}_{2}$ efflux: an in-situ comparison of four techniques, Tree Physiol., 20, 23-32, 2000.

Koskinen, M., Minkkinen, K., Ojanen, P., Kämäräinen, M., Laurila, T., and Lohila, A.: Measurements of $\mathrm{CO}_{2}$ exchange with an automated chamber system throughout the year: challenges in measuring night-time respiration on porous peat soil, Biogeosciences, 11, 347-363, https://doi.org/10.5194/bg-11-347-2014, 2014.

Kostyanovsky, K., Huggins, D., Stockle, C., Waldo, S., and Lamb, B.: Developing a flow through chamber system for automated measurements of soil $\mathrm{N}_{2} \mathrm{O}$ and $\mathrm{CO}_{2}$ emissions, Measurement, 113, 172-180, 2018.

Merbold, L., Wohlfahrt, G., Butterbach-Bahl, K., Pilegaard, K., DelSontro, T., Stoy, P., and Zona, D.: Preface: Towards a full greenhouse gas balance of the biosphere, Biogeosciences, 12, 453-456, https://doi.org/10.5194/bg-12-453-2015, 2015.

Nickerson, N.: Evaluating gas emission measurements using Minimum Detectable Flux (MDF), Eosense Inc., Dartmouth, Nova Scotia, Canada, 2016.

Nicolini, G., Castaldi, S., Fratini, G., and Valentini, R.: A literature overview of micrometeorological $\mathrm{CH}_{4}$ and $\mathrm{N}_{2} \mathrm{O}$ flux measurements in terrestrial ecosystems, Atmos. Environ., 81, 311-319, 2013.

O'Connell, C. S., Ruan, L., and Silver, W. L.: Drought drives rapid shifts in tropical rainforest soil biogeochemistry and greenhouse gas emissions, Nat. Commun., 9, 1348, https://doi.org/10.1038/s41467-018-03352, 2018.

Oertel, C., Matschullat, J., Zurba, K., Zimmermann, F., and Erasmi, S.: Greenhouse gas emissions from soils-A review, Chem. ErdeGeochem., 76, 327-352, 2016.

Petitjean, C., Hénault, C., Perrin, A.-S., Pontet, C., Metay, A., Bernoux, M., Jehanno, T., Viard, A., and Roggy, J.-C.: Soil $\mathrm{N}_{2} \mathrm{O}$ emissions in French Guiana after the conversion of tropical forest to agriculture with the chop-and-mulch method, Agr. Ecosyst. Environ., 208, 64-74, 2015.

Petrakis, S., Seyfferth, A., Kan, J., Inamdar, S., and Vargas, R.: Influence of experimental extreme water pulses on greenhouse gas emissions from soils, Biogeochemistry, 133, 147-164, 2017a. 
Petrakis, S., Barba, J., Bond-Lamberty, B., and Vargas, R.: Using greenhouse gas fluxes to define soil functional types, Plant Soil, $1-10,2017 \mathrm{~b}$.

Pumpanen, J., Kolari, P., Ilvesniemi, H., Minkkinen, K., Vesala, T., Niinistö, S., Lohila, A., Larmola, T., Morero, M., and Pihlatie, M.: Comparison of different chamber techniques for measuring soil $\mathrm{CO}_{2}$ efflux, Agr. Forest Meteorol., 123, 159-176, 2004.

Rowland, L., Hill, T. C., Stahl, C., Siebicke, L., Burban, B., Zaragoza-Castells, J., Ponton, S., Bonal, D., Meir, P., and Williams, M.: Evidence for strong seasonality in the carbon storage and carbon use efficiency of an Amazonian forest, Glob. Change Biol., 20, 979-991, 2014.

Rubio, V. E. and Detto, M.: Spatiotemporal variability of soil respiration in a seasonal tropical forest, Ecol. Evol., 7, 7104-7116, 2017.

Savage, K., Phillips, R., and Davidson, E.: High temporal frequency measurements of greenhouse gas emissions from soils, Biogeosciences, 11, 2709-2720, https://doi.org/10.5194/bg-112709-2014, 2014.
Silver, W. L., Lugo, A., and Keller, M.: Soil oxygen availability and biogeochemistry along rainfall and topographic gradients in upland wet tropical forest soils, Biogeochemistry, 44, 301-328, 1999.

Teh, Y. A., Diem, T., Jones, S., Huaraca Quispe, L. P., Baggs, E., Morley, N., Richards, M., Smith, P., and Meir, P.: Methane and nitrous oxide fluxes across an elevation gradient in the tropical Peruvian Andes, Biogeosciences, 11, 2325-2339, https://doi.org/10.5194/bg-11-2325-2014, 2014.

Verchot, L. V., Davidson, E. A., Cattânio, H., Ackerman, I. L., Erickson, H. E., and Keller, M.: Land use change and biogeochemical controls of nitrogen oxide emissions from soils in eastern Amazonia, Global Biogeochem. Cy., 13, 31-46, 1999.

Verchot, L. V., Davidson, E. A., Cattânio, J. H., and Ackerman, I. L.: Land-use change and biogeochemical controls of methane fluxes in soils of eastern Amazonia, Ecosystems, 3, 41-56, 2000.

Wagner, F., Hérault, B., Stahl, C., Bonal, D., and Rossi, V.: Modeling water availability for trees in tropical forests, Agr. Forest Meteorol., 151, 1202-1213, 2011. 